\title{
Failure to Recognize Status Epilepticus in a Paralysed Patient
}

\author{
R.I. Munn and K. Farrell
}

\begin{abstract}
Paralysis induced by neuromuscular blocking agents facilitates ventilation of seriously ill patients but may preclude clinical recognition of seizures. We describe the occurrence of severe cognitive impairment in a 14-yearold girl in whom status epilepticus was recognized only when pancuronium was withdrawn after 14 hours of paralysis. This patient emphasizes a potential danger of paralysis from drugs in patients with acute cerebral dysfunction.

RÉSUMÉ: État de mal épileptique non reconnu chez une patiente paralysée. La paralysie induite facilite la ventilation chez les patients gravement malades, mais peut empêcher l'observation de manifestations épileptiques. Nous décrivons l'apparition d'un déficit cognitif sévère chez une fille de 14 ans, chez qui un état de mal épileptique n'a été reconnu qu'au moment où le pancuronium a été cessé, après 14 heures de paralysie. Ce cas souligne le danger potentiel de la paralysie induite chez les patients qui ont une dysfonction cérébrale aiguë.
\end{abstract}

Can. J. Neurol. Sci. 1993; 20: 234-236

Neuromuscular blocking agents, commonly used to facilitate ventilation in the critically ill patient, may preclude clinical recognition of seizures. We describe the development of serious cognitive impairment in a patient in whom the presence of status epilepticus was not recognized until paralysis was withdrawn.

\section{CASE REPORT}

A fourteen-year-old girl presented in March 1988, with a five day history of fever, headache, vomiting and diarrhoea. A few hours prior to admission she became confused and unable to recognize her parents. On physical examination she was febrile $\left(38.9^{\circ}\right)$, disoriented and combative. There were no focal neurological signs.

The child was paralysed and ventilated in order to perform a computed tomography (CT) head scan. Intravenous morphine and pancuronium was administered over 14 hours in order to facilitate ventilation. Shortly after pancuronium was discontinued, continuous twitching of the facial muscles, deviation of the eyes to the right and clonic movements of all four extremities were observed. Scalp electrodes were being applied at this time but only the right sided leads were in place. Spike and wave discharges over the right hemisphere were demonstrated on the electroencephalogram (EEG) (Figure).

The patient was treated with intravenous diazepam and phenytoin. The generalized seizure stopped within five minutes and left facial twitching was observed for a further 20 minutes. The EEG demonstrated an active left temporal spike focus with independent right fronto-temporal spikes. The child remained comatose and was ventilated for six days, during which time generalized clonic seizures lasting 2-3 minutes occurred $3-4$ times per day and were treated with phenobarbital. Following extubation, brief complex partial seizures were observed until carbamazepine was added to her treatment. She received acyclovir for 10 days and was discharged home on phenobarbital, phenytoin and carbamazepine.
The underlying cause of the child's neurological condition and status epilepticus was not demonstrated. A CT head scan without contrast was normal. An EEG performed five days after the episode of status epilepticus showed diffuse suppression with multifocal delta activity. Lumbar puncture (bloody tap) revealed $420 \times 10^{6} / \mathrm{L}$ red blood cells and $<1 \times$ $10^{6} / \mathrm{L}$ nucleated cells (normal $<6 \times 10^{6} / \mathrm{L}$ ). Cerebrospinal fluid (CSF) glucose was $3.3 \mathrm{mmol} / \mathrm{L}$ (normal $2.8-4.4 \mathrm{mmol} / \mathrm{L}$ ) and CSF protein $0.48 \mathrm{~g} / \mathrm{L}$ (normal $0.15-0.45 \mathrm{~g} / \mathrm{L}$ ). Bacterial and viral cultures were negative. Viral serology for cytomegalovirus, herpes simplex, varicella zoster, Epstein Barr virus, influenza, measles, mumps, and rubella were negative. ESR was elevated at $34 \mathrm{~mm} / \mathrm{h}$. The following investigations were normal: hemoglobin, white blood count, platelet count, antinuclear antibody, drug screen, electrolytes, bicarbonate, urea, creatinine, glucose, calcium, phosphate, magnesium, ammonia, bilirubin, alkaline, phosphatase, aspartate aminotransferase, amylase, albumin, blood gases.

Prior to her illness, this child had developed normally and was an above average student in grade 8 . Following discharge she was dysphasic, had marked difficulty with recent memory and could not cope at school Initial neuropsychological testing performed two months after the episode demonstrated intellectual function within the mentally retarded range with a superimposed moderately severe dysphasia. Serial psychologic testing has shown a gradual improvement in cognitive function but this patient has had persistent difficulty with repetition, naming and comprehension and requires modified school courses. She continues to have approximately one complex seizure per month and receives carbamazepine and nitrazepam.

\section{Discussion}

The cause of this girl's marked cognitive impairment is uncertain. The clinical presentation of fever, diarrhoea, headache, altered mental status and seizures suggest that this

From the Department of Paediatric Neurology, University of British Columbia, Vancouver

Received July 30, 1992. Accepted in final form January 25, 1993

Presented in part at the Canadian Congress of Neurological Sciences, June 1990, Banff, Alberta

Reprint requests to: Dr. Kevin Farrell, Neurology Department, British Columbia's Children's Hospital, 4480 Oak Street, Vancouver, British Columbia, Canada V6H 3 V4 


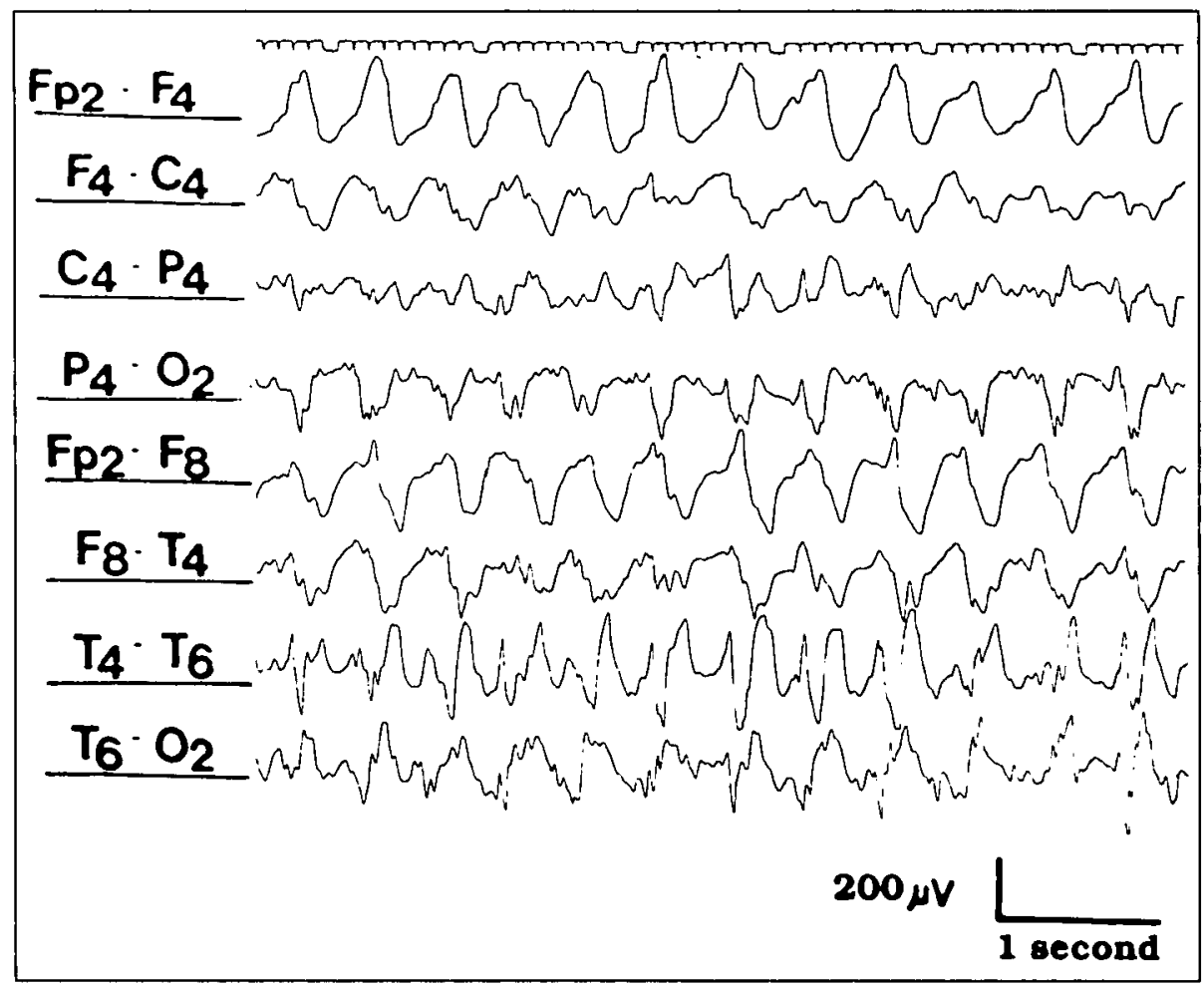

Figure - An EEG performed with only the right sided leads in place demonstrates contimuous diffuse spike-w'ave discharges over the right hemisphere. During this recording. generalised clonic novements were observed.

child may have had an infectious encephalopathy. However, there was no CSF pleocytosis, a virus was not cultured from the $\mathrm{CSF}$, and the serology did not demonstrate a rise in titres against the viruses tested. The possibility that prolonged status epilepticus occurred in this child is raised by the clinical recognition of the seizure as soon as paralysis was withdrawn. Because of the duration of the paralysis, status epilepticus may have contributed, at least in part, to her protracted comatose state and her present cognitive impairment.

Untreated prolonged seizures in experimental animals result in neurochemical and neuronal ischemic changes. ${ }^{1.2}$ Prevention of hypoxia by paralysis and ventilation during prolonged seizures in experimental animals does not protect against neuronal injury or death. ${ }^{2.3}$ Prolonged convulsive status epilepticus in children is associated with both mortality and neurologic morbidity. ${ }^{4-6}$ Of 239 children with an episode of status epilepticus lasting at least one hour, 10 died during the seizure, 47 developed abnormal neurological signs and 78 children had mental retardation which was felt to be acquired at the time of the prolonged seizure. ${ }^{4}$ A lower neurologic morbidity has been described in recent series of status epilepticus and may relate to a more aggressive approach to seizure control.5,6

Continuous, multi-channel, electroencephalographic (EEG) recording is the only reliable method of detecting epileptic seizures. This method has been shown to be useful in the detection of seizures in paralysed newborns, particularly following perinatal asphyxia. ${ }^{78}$ The cost involved and the technical expertise necessary for intensive EEG monitoring limit the availability of this method in the intensive care setting. ${ }^{9}$ Continuous electro- physiologic monitoring of cerebral function, in which a single pair of scalp electrodes are used and voltage and frequency are plotted against time, has been proposed as a method of monitoring paralysed patients with seizures. ${ }^{10.12}$ However, the interpretation of cerebral function monitoring data requires that multichannel EEGs be performed at baseline and at intervals thereafter. ${ }^{9}$ Furthermore, this method is neither sensitive nor specific and there have been no adequate controlled studies demonstrating its effectiveness in the detection of epileptic seizures. ${ }^{9}$ Consequently, cerebral function monitoring using two electrodes is not an adequate substitute for continuous EEG monitoring. When continuous EEG monitoring is not available. prophylactic treatment with an anticonvulsant and intermittent reversal of paralysis to permit assessment of the patient should be used.

This patient illustrates a potentially serious complication of paralysis in the patient with an acute encephalopathy. When neuromuscular blocking agents must be used, steps should be taken to detect and prevent seizures.

\section{REFERENCES}

1. Duffy TE, Howse DC, Plum F. Cerebral energy metabolism during experimental status epilepticus. J Neurochem 1975; 24: 925-934.

2. Meldrum BS, Vigouroux RA, Rage P, Brierley JB. Hippocampal lesions produced by prolonged seizures in paralysed artificially ventilated baboons. Experientia 1973; 29: 561-563.

3. Wasterlain CG. Mortality and morbidity from serial seizures. Epilepsia 1974; 15: 155-176.

4. Aicardi J, Chevrie JJ. Convulsive status epilepticus in infants and children. A study of 239 cases. Epilepsia 1970; 11: 187-197. 
5. Yager JY, Cheang M, Seshia SS. Status epilepticus in children. Can J Neurol Sci 1988; 15: 402-405

6. Maytal J, Shinnar S, Moshe SL, Alvarez LA. Low morbidity and mortality of status epilepticus in children. Pediatrics 1989; 83: 323-331.

7. Eyre JA, Oozeer RC, Wilkinson AR. Continuous electroencephatographic recording to detect seizures in paralysed newborn babies. Brit Med J 1983; 286: 1017-1018.

8. Coen RW, McCutchen CB, Wermer D, Snyder J, Gluck FE. Continuous monitoring of the electroencephalogram following perinatal asphyxia. J Pediatr 1982; 100: 628-630.
9. Talwar D, Torres F. Continuous electrophysiologic monitoring of cerebral function in the pediatric intensive care unit. Pediatr Neurol 1988; 4: 137-147.

10. Prior PF, Virden RSM, Maynard DE. An EEG device for monitoring seizure discharges. Epilepsia 1973; 14: 367-372.

11. Partinen M, Kovanen J, Nilsson E. Status epilepticus treated by barbiturate anaesthesia with continuous monitoring of cerebral function. Brit Med J 1981; 282: 520-521.

12. Hellström-Westas L, Rosén I, Swenningsen NW. Silent seizures in sick infants in early life - diagnosis by continuous cerebral function monitoring. Acta Paediatr Scand 1985; 74: 741-748. 